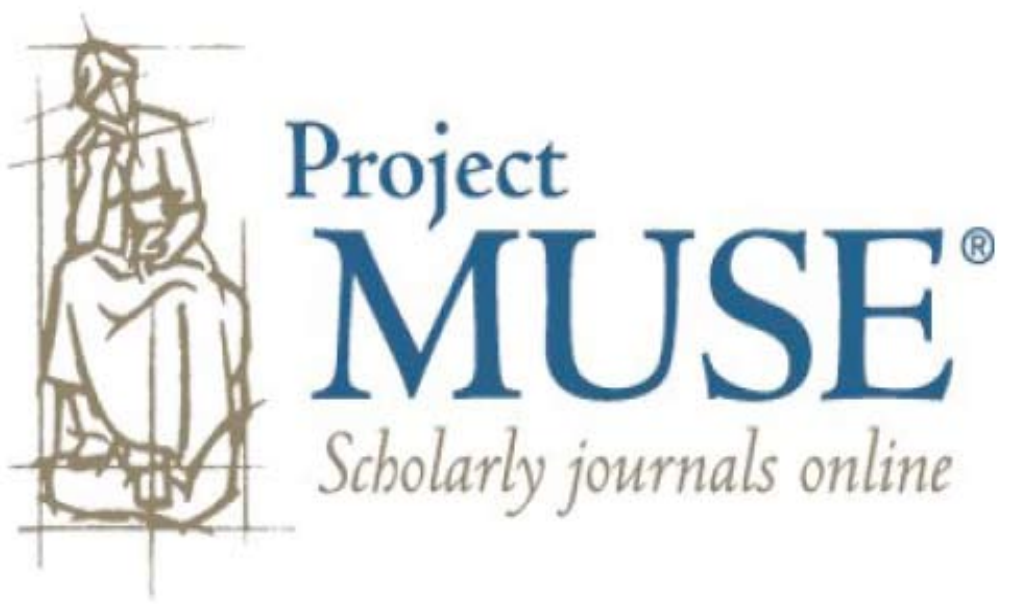




\title{
Assessing Health Concerns and Barriers in a Heterogeneous Latino Community
}

\author{
Iveris L. Martinez, PhD \\ Olivia Carter-Pokras, $\mathrm{PhD}$
}

\begin{abstract}
Introduction. Major health issues and barriers to health services for Latino immigrants were identified through community-based participatory research in Baltimore city. Methods. In collaboration with community partners, five focus groups were conducted among Latino adults from 10 countries and health service providers. Findings. Priorities across groups included chronic diseases, HIV/AIDS and STDs, mental health, and the need for ancillary services. Community members and providers did not always agree on what health matters were of primary concern. Participants expected to receive health information at the point of service. Barriers to receiving health services and information span linguistic, financial, logistical, legal, and cultural matters. Conclusions. This formative research illustrates the complexity and interrelatedness of health priorities and barriers created by social issues such as employment, legal status, and related stressors.
\end{abstract}

Key words: Hispanic Americans, community-based participatory research, needs assessment, minority groups, health services accessibility.

n increasingly diverse and growing population, ${ }^{1}$ Latinos present challenges in
health care access and service delivery at the local level that include, but are
not limited to, limited English language proficiency and lack of health insurance. ${ }^{2-3}$
Nationally, disparities in access to health care, risk factors (e.g., obesity), and mor-
bidity (e.g., diabetes) disfavor Latinos under 65 years of age in comparison with
their non-Latino White (NLW) counterparts. ${ }^{4-7}$ Information that is relevant for
addressing disparities at the local level where services are rendered is sparse. ${ }^{8}$
While Latinos appear to have lower overall mortality in adulthood than NLWs,
this mortality advantage holds largely for immigrant Mexicans, Dominicans, and
Central and South Americans. ${ }^{9}$ Latinos receive lower quality of care than NLWs for
half of the available quality measures and have worse access to care for about $90 \%$
of access measures. ${ }^{4}$ In Maryland, the uninsured rate among low-income Latinos
is $64 \%$, the highest for any population subgroup. ${ }^{10}$
Maryland's Latino population is the fastest growing minority group in the state
(5.4\% in 2004). ${ }^{11}$ In $2004,2.2 \%$ (13,204) of Baltimore City's population (10\% in

IVERIS MARTINEZ is a Research Associate at the Johns Hopkins University Center on Aging and Health in Baltimore and can be reached at imartinez@jhmi.edu. OLIVIA CARTER-POKRAS is an Associate Professor in the Department of Epidemiology and Preventive Medicine at the University of Maryland School of Medicine. 
Southeast Baltimore) was Latino. ${ }^{12}$ Community leaders and providers, who have seen an unprecedented increase in service usage, believe that official estimates are undercounts due to immigration and legal status concerns. Despite a general lack of information on the health status of Latinos in Baltimore City, there is growing recognition of the challenges to health care access for this population. ${ }^{13-14}$

To better understand the health of Latinos in Baltimore, ${ }^{15}$ and to provide formative data for community-based interventions and future research, we conducted five focus groups with community members and service providers under the direction of a Community Advisory Board (CAB). Community-based participatory research (CBPR) incorporates community input at all stages of the research process to enhance capacity building and overcome barriers to research raised by matters of trust, communication, cultural differences, power, and representation. ${ }^{17-20}$

\section{Methods}

Prior Institutional Review Board approval was obtained from Johns Hopkins University and the University of Maryland.

Population recruitment. Established with the aid of a city-wide network of service providers, a $\mathrm{CAB}$ including representatives from local universities and community service agencies recruited focus group participants. Inclusion criteria for the community member focus groups were self-identification as Latino, and residence, work, or receipt of services in Baltimore City. Health service providers in Baltimore City were recruited in order to compare their perspectives with those of the community they serve.

Focus group participants were recruited to one of five focus groups: 18-59 year old women $(n=6), 18-59$ year old men $(n=4)$, parents of children under 18 years of age $(n=11)$, Latinos at least 60 years of age $(n=6)$, and health service providers $(n=7)$. This factorial design allowed us to control for sex and age in our analysis, ${ }^{20-21}$ to facilitate discussion among peer groups, and to enable discussion of potentially sensitive gender-specific health issues. ${ }^{22}$

\section{Table 1.}

\section{DESCRIPTION OF FOCUS GROUPS}

\begin{tabular}{llc}
\hline \hline Code & Description & Number participants \\
\hline OW & Women, ages 60 and over & 6 \\
AW & Women, ages 18-59 & 6 \\
PA & Parents with children ages 17 and under & 11 \\
AM & Adult men, ages 18 and over & 4 \\
SP & Health providers & 7 \\
TOTAL & & 34 \\
\hline
\end{tabular}


Data collection and analysis. In addition to recruiting participants, the $\mathrm{CAB}$ decided on the amount of participant compensation, collaborated in the development of the focus group moderator guide and demographics questionnaire, and participated in the dissemination of findings. Focus groups were co-facilitated by community members who were trained by the bilingual principal investigator (IM). Community member focus group discussions were conducted in Spanish, and the provider focus group discussion was conducted in English. Each focus group lasted approximately one hour and was guided by four key research questions: 1) What health issues do Latino residents and providers prioritize? 2) Where do Latino residents receive health services and information? 3) What are the perceived barriers to health care access? 4) Are there important differences between the perspective of providers and that of Latino residents of Baltimore City?

A nominal group process was conducted at the end of the discussion by listing the responses under each question and asking participants to rank the three items of greatest importance. ${ }^{23-24}$ Participant demographic characteristics collected with a brief self-administered questionnaire included age, sex, education, date of arrival in the U.S. and in Baltimore, immigration status, and health insurance coverage. Co-facilitators recorded detailed notes in the language used for discussion, and participated in a facilitator debriefing at the end of each discussion. Discussions were audio-taped, translated from Spanish, and transcribed in English. Responses were analyzed through comparison of notes, and review of written transcription for prioritized content and recurring themes.

\section{Results}

Demographics of sample. Latino community member focus group participants originated in 10 countries: Dominican Republic, Ecuador, El Salvador, Guatemala, Mexico, Panama, Peru, Puerto Rico, United States, Venezuela (Table 2). Year of arrival in Baltimore ranged from 1950 to 2001 (focus groups were held in 2003), and the majority of participants (77\%) were not U.S. citizens. Residing largely in southeast Baltimore City, participants ranged in age from 21 to 90 years with 2 to 16 years of education.

Provider focus groups included 7 local health care providers (4 physicians, 1 nurse, 1 public health practitioner, and 1 health educator) from a variety of settings (community health agencies, hospitals, and private practices) serving southeast Baltimore. Five of the providers considered themselves fluent in Spanish. On average, the group had been working in Baltimore City since 1986. The providers reported seeing 6 to 55 Latino patients per week in their individual practices (mean, 31). One community clinic reported averaging 175 Latino patients per week.

Top health concerns. Though top health concerns varied across groups, there were striking similarities (Table 3). High blood pressure and heart disease, and stress, anxiety, and mental health issues were mentioned in four of the five focus groups. Diabetes, asthma, AIDS, and STDs were mentioned by three of the five focus groups. Dental health, alcohol and drug abuse, and influenza were mentioned by two of the five focus groups. 


\section{Table 2.}

CHARACTERISTICS OF COMMUNITY MEMBER FOCUS GROUP PARTICIPANTS

\begin{tabular}{lccc}
\hline \hline & Range & Mean & Median \\
\hline Age (in years) & $21-90$ & 46 & 41 \\
Excluding seniors & $21-48$ & 38 & 39 \\
Year of arrival & $1950-2001$ & 1992 & 1997 \\
Percent female & 85 & & 9 \\
Years of education & $2-16$ & 9 & \\
Percent United States citizen & 23 & & \\
Percent without health insurance & 74 & & \\
Number countries represented & $10^{\text {a }}$ & & \\
aDominican Republic, Ecuador, El Salvador, Guatemala, Mexico, Panama, Peru, Puerto Rico, USA, \\
Venezuela.
\end{tabular}

Community members and providers did not always agree on what health matters were of primary concern. Notably, providers did not identify AIDS and STDs, asthma and respiratory problems, or influenza as top health concerns for the Latino community. Neonatal and pediatric care, and preventative care for chronic diseases were identified by providers as top health concerns, but not specifically mentioned by the community members.

Providers expressed the view that high blood pressure, heart disease, and diabetes were key concerns in this community, and noted a need for preventive care for chronic diseases. One said, "Preventative care is a barrier because they are waiting until they are very sick to seek help. They are not getting screened for years." They expressed frustration that they often saw patients with advanced stages of chronic diseases when it is "too late."

Mental health issues recurred repeatedly as a theme ranging from general mental health concerns to stress, anxiety (nervios), and alcohol and substance abuse issues. Providers as well as lay people noted anxiety as an issue. The men's group linked alcohol and substance abuse with interpersonal and domestic violence. Stress related to legal status, employment, and costs of health care was perceived by community members as a main contributor to mental health concerns. Many participants had received large bills from emergency room visits or knew someone else who had. 


\section{Table 3.}

\section{TOP HEALTH CONCERNS ${ }^{\mathrm{a}}$}

Older Women

1. "Bone-related disease" (arthritis/osteoporosis)

2. Heart (hypertension/cholesterol)

3. Stress/mental health (nervios)

4. Respiratory problems (allergies/asthma), diabetes (glucosa), influenza, AIDS

Women

1. Diabetes

2. Hypertension (presión)

3. Eye problems (la vista)

4. AIDS, cancers (breast and uterine), influenza (virus de la gripe), gastritis, hearing/ dental, stress/mental health

Men

1. Alcohol and drug abuse

2. Mental health

3. STDs

4. Violence and domestic issues, respiratory problems (allergies/asthma), nutrition (hypertension/ cholesterol)

Parents

1. Ear infections

2. Asthma

3. Lead poisoning

4. Stomach viruses, fevers, coughs

Providers

1. Neonatal \& pediatric care

2. Preventive care for chronic disease

3. Diabetes \& heart disease

4. Dental, alcohol and substance abuse, anxiety/mental health

${ }^{a}$ Top 3 items in each category were ranked 1st by at least 3 participants in each group.

OW ${ }^{*}$ : I think stress leads to a lot of other health issues ... emotional insecurity.

AW1: Stress ... sometimes this makes you depressed

AW2: I think there are a lot of emotional problems [in the community].

Sources of health services and information. Promptness and politeness were important in determining good service. Parents reported seeking services for their

\footnotetext{
${ }^{*}$ Abbreviations used in describing focus group participants: $\mathrm{OW}=$ woman, age 60 years or older; AW=woman, age 18-59 years; $\mathrm{PA}=$ parent with child(ren) aged 17 years or younger; $\mathrm{AM}=$ adult man, age 18 years or older; $\mathrm{SP}=$ health service providers.
} 
children at places where they perceive service is better. Adults tended to postpone health care visits for themselves until they required emergency room services. Many community members said that they relied on home remedies in non-emergency situations due to lack of access to providers.

Latinos who participated in the focus groups generally expected to receive information during their visit with a doctor or other health care provider, usually at one of three community agencies and five hospitals. One participant remarked, "I went to a dermatologist and he told me what I had but did not explain to me what it was. So I had to look for information about it."

Community members relied heavily on their children's social workers, mass media (television, radio), word-of-mouth, and networks of friends to obtain health information. Some providers were aware of these networks. One provider said, "There is a sub-culture ... they have networks and they share ideas and resources with each other." Generally, however, providers were not members of these networks nor did they have a mechanism for sharing resources among themselves.

Barriers to access. Barriers to health services and information faced by Latinos in Baltimore go beyond the better known linguistic and financial barriers to include logistical, legal, and cultural barriers (Box 1). Three-quarters of community members did not have health insurance. There is a perceived association between lack of health insurance and poor quality health care.

OW1: Insurance is a problem ... when you go to the hospital, they say "Do you have insurance?" and if you say no they tell you then just take a Tylenol. Unless it is a car accident or a matter of death they don't do the right tests.

OW2: I was in the hospital and they charged me $\$ 2,000$ for nothing. They didn't do anything.

OW3: Your legal status ... some people are afraid to go to the hospital. They don't know their rights.

OW4: My daughter was in the emergency room for four hours screaming with pain and they wouldn't see her because she didn't have insurance.

Providers acknowledged that health, and especially children's health, was a priority for Latinos, but noted that some patients/clients viewed health insurance in terms of costs and benefits rather than risks and benefits.

SP1: I got a call from a woman who was given the option of health insurance for \$37 a month but she couldn't afford it because she had to send money back home ... I think they don't see the risk that something may happen that requires a lot of care ... she was thinking well last year I only saw the doctor twice and that is not worth $\$ 37$ a month. She saw it as a cost benefit instead of a risk benefit.

SP2: I came across a woman who needed surgery and turns out her husband had a health insurance policy on himself because he worked construction and they required him to, but when he considered the cost to add his family on ... he chose not to. 


\section{Box 1.}

\section{BARRIERS TO ACCESS}

Linguistic

- Absence of personnel who speak Spanish

- Lack of written information in Spanish

- Inability to speak English

- Poorly translated materials

- Untrained and unqualified interpreters

- Inability to fill out personal information forms

Cultural

- Expectation of poor service

- Expectation of long waits

- Lack of culturally competent providers

Financial

- Lack of health insurance

- View of health insurance in terms of cost-benefit rather than risk-benefit

- Prohibitive costs

- Inadequate funds to pay for health services needed

Legal

- Lack of a social security number

- Fear that their immigrant status may affect their ability to obtain proper care

Logistical

- Inability to leave their place of employment to attend to medical needs

- Lack of transportation

- Absence of conveniently located services

- Waiting time to obtain an interpreter

Affordable health insurance is not the only financial barrier. One adult woman said, "It doesn't matter if you have insurance or not except if you need to see a specialist ... either way you need to have money." Prohibitive costs and inadequate funds lead to not seeking preventive services. Both community members and providers agreed that financial barriers lead many to delay seeking health care, except for children for whom parents sought services despite financial limitations.

Also mentioned were logistical barriers to care such as lack of transportation, absence of conveniently located health services, hours of operation, and inability of many participants to leave their place of employment to attend to their own or their children's medical needs.

AW1: Sometimes there is no time or you have to work

AW2: ... there need to be services after 5 or $6 \mathrm{pm}$. 
AW3: And on Saturdays and Sundays.

AW4: Sometimes the employee doesn't communicate with his employer and they don't get the time off work or it is not paid.

Once patients do get to the available health care providers, there may be long waiting times and waits to obtain an interpreter. As one participant described the situation, "If you don't have anyone to interpret for you then you just have to wait."

Legal status became a barrier to accessing services for many community members due to lack of a Social Security number (required for registering for some services) and fear of being singled out at the point of service. The expectation of poor service and long waits, and lack of medical interpreters and culturally competent providers acted as additional barriers to accessing the limited services available to this community.

Providers' barriers and needs. Providers recognized that one of the top needs of the community is "access and comfort with access to care." The group then discussed numerous linguistic and cultural barriers. One provider said, "I think many Latinos coming here from other countries are not comfortable with filling out their paper work and such . . . it is hard when the front desk doesn't speak Spanish or there is a big security guard at the door and that can be intimidating ... they come in but they don't know where to go."

Cultural competence was seen as an issue by community members and providers. Providers were interested in learning how to build trusting relationships with Latino patients, in order to understand health beliefs and home remedies commonly used by Latinos, and to learn about resources for referring their patients. Community strengths identified by providers included strong families and networks, desire to comply with doctor's orders (especially in prenatal care), concern for children's health and education, and a strong work ethic. Providers felt the community needed to have a better understanding of the medical system and insurance practices.

\section{Discussion}

Health concerns identified most often included chronic diseases (diabetes, heart disease, asthma), AIDS and STDs, mental health problems (stress, anxiety, alcohol and substance abuse), and vision, hearing and dental service needs. As the focus groups were conducted separately, we were unable to fully explore why community members and providers disagreed on health priorities. Few quantitative data exist regarding Latino health in Baltimore. However, community members may have greater knowledge of the health problems of their friends or family, as well as exposure to media reports on Latino health. Cultural barriers and the need for improved access to preventive and ancillary services were identified.

Limitations of this study include its exploratory nature, the small number of Latino men participating, and an inability to generalize our findings. Open-ended discussions in focus groups provided local in-depth data pointing to the complex- 
ity and interrelatedness of health priorities and barriers with social issues (such as employment, legal status, and related stressors).

Community-based participatory research (CBPR) is valuable in achieving a greater understanding of the socio-economic, political, and cultural factors influencing health beyond traditional public health and medical models. The iterative process of CBPR facilitates feedback to the community (including providers). Information from these focus groups on preferred modes of interviewing, recruitment, and participation has already been used in the design of a health interview survey of Latinos in Baltimore. ${ }^{25}$ In addition, this information has been used to plan intervention projects on diabetes and eye disease, and on arthritis.

\section{Conclusion}

This paper demonstrates the value of CBPR for addressing health and approaching access issues in a medically underserved community. It provides local data on health priorities and barriers for Latinos and the differences between the perspective of providers and those of community members. In order to address health disparities, there is a need for improved access to preventive and ancillary services (including dental, hearing, vision, mental health), screening and follow-up for chronic illnesses for medically underserved populations, and systematic communication between providers and the community they serve. Latino immigrants need education on the health care system, available services, rights, and communication with providers. Linguistic barriers to access still must be addressed. ${ }^{3}$ To become more culturally competent, providers should learn more about the community they serve, and establish networks to provide services for their patient populations.

\section{Acknowledgments}

The data collection and preliminary analysis were supported by the Johns Hopkins Bloomberg School of Public Health W.K. Kellogg Community Health Scholars Program for post-doctoral training in community-based participatory research in partnership with a local community-based organization. We would like to acknowledge Carmen Nieves M.P.A, and the staff of Centro de la Comunidad, Inc. for their key role in this Project, as well as the Members of the Community Advisory Board who generously donated their time to this endeavor, and the Latino Providers Network for their support of this project. Audiotape transcriptions and final analyses of the focus group data were funded by the University of Maryland Statewide Health Network.

\section{Notes}

1. United States Census Bureau Population Division. Table 4: Annual Estimates of the Population by Race Alone and Hispanic or Latino Origin for the United States and States: July 1, 2004. (SC-EST2004-04.) Washington, DC: U.S. Census Bureau, 2005 Aug 11. 
2. Zambrana RE, Carter-Pokras O. Improving health insurance coverage for Latino children: a review of barriers, challenges and state strategies. J Natl Med Assoc. 2004 Apr;96(4):508-23.

3. Carter-Pokras O. Providing linguistically appropriate devices to persons with limited English proficiency: a need and resources investigation. Am J Manag Care. 2004 Sep;10 Spec No: SP29-36.

4. Agency on Health Research and Quality (AHRQ). National Healthcare Disparities Report. Rockville MD: Department of Health and Human Services, AHRQ, 2004.

5. National Center for Health Statistics (NCHS). Health, United States, 2005 with chartbook on trends in the health of Americans. Hyattsville, MD: NCHS, 2005.

6. Carter-Pokras O, Zambrana RE. Latino health status. In: Aguirre-Molina M, Molina CW, Zambrana RE, eds. Health issues in the Latino community. San Francisco: JosseyBass, 2001; 23-54.

7. Centers for Disease Control and Prevention (CDC). Health disparities experienced by Hispanics. MMWR Morb Mortal Wkly Rep. 2004 Oct 15;53(40):935-7.

8. Zambrana RE, Carter-Pokras O. Health data issues for Hispanics: implications for public health research. J Health Care Poor Underserved. 2001 Feb;12(1):20-34.

9. Palloni A, Arias E. Paradox lost: explaining the Hispanic adult mortality advantage. Demography. 2004 Aug;41(3):385-415.

10. Maryland Health Care Commission (MHCC). Health insurance coverage in Maryland through 2003. Baltimore, MD: MHCC, 2004 Nov.

11. U.S. Census Bureau Population Division. Table 3: Annual Estimates of the Population by Sex, Race and Hispanic or Latino Origin for Maryland: April 1, 2000 to July 1, 2004. (SC-EST2004-03-24.) Washington, DC: U.S. Census Bureau, 2005 Aug 11.

12. United States Census Bureau. American Community Survey 2004. Washington, DC: U.S. Census Bureau, 2005

13. Brewington K. Health care options limited for many Baltimore Latinos. Checkup: survey finds few have insurance as hospitals struggle to provide interpreters for the growing group. Baltimore Sun. 2004 Nov 15:1A.

14. Green AA. Ehrlich cuts health care for children of immigrants: administration also weighs fate of funds for pregnant women. Baltimore Sun. 2005 Jun 22:1A.

15. Oliver A, Mossialos E. Equity of access to health care: outlining the foundations for action. J Epidemiol Community Health. 2004 Aug;58(8):655-8.

16. Geiger HJ. Community-oriented primary care: a path to community development. Am J Public Health. 2002 Nov;92(11):1713-6.

17. Minkler M, Wallerstein N, eds. Community-based participatory research for health. San Francisco, CA: Jossey-Bass, 2002.

18. Palafox N, Buenconsejo-Lum L, Riklon S, et al. Improving health outcomes in diverse populations: competency in cross-cultural research with indigenous Pacific Islander populations. Ethn Health. 2002 Nov;7(4):279-85.

19. O’Toole TP, Aaron KF, Chin MH, et al. Community-based participatory research. J Gen Intern Med. 2003 Jul;18(7):592-4.

20. Bernard HR. Research methods in anthropology: qualitative and quantitative approaches, 3rd Ed. Walnut Creek, CA: AltaMira Press, 2002.

21. Knodel J, Havanon N, Pramualratana A. Fertility transition in Thailand: a qualitative analysis. Population and Development Review. 1984 Jun;10(2):297-328.

22. Morgan DL, Krueger RA. The focus group kit. Thousand Oaks, CA: Sage, 1998. 
23. Gallagher M, Hares T, Spencer J, et al. The nominal group technique: a research tool for general practice? Fam. Pract. 1993 Mar;10(1):76-81.

24. Miller D, Shewchuk R, Elliot TR, et al. Nominal group technique: a process for identifying diabetes self-care issues among patients and caregivers. Diabetes Educ. 2000 Mar-Apr;26(2):305-10, 312, 314.

25. Carter-Pokras O, Solano H, Brown P, et al. General Health Assessment of Latinos in Baltimore. (abstract 554). Am J Epidemiol 2005 Jun 1;161(11 Suppl):S139. 